\title{
Optimization and Characterization of Wood Vinegar Produced by Shorea laevis Ridl Wood Pyrolysis
}

\author{
Hasan Ashari Oramahi ${ }^{1, *}$, Tsuyoshi Yoshimura ${ }^{2}$, Elvi Rusmiyanto ${ }^{3}$, and Kustiati ${ }^{3}$ \\ ${ }^{1}$ Faculty of Forestry, University of Tanjungpura, Jl. Daya Nasional, Pontianak 78124, Indonesia \\ ${ }^{2}$ Research Institute for Sustainable Humanosphere (RISH), Kyoto University, Uji, 611-0011 Kyoto, Japan \\ ${ }^{3}$ Faculty of Mathematics and Natural Sciences, University of Tanjungpura, \\ Jl. Prof. Dr. H. Hadari Nawawi, Pontianak 78124, Indonesia
}

* Corresponding author:

email:oramahi@fahutan.untan.ac.id

Received: May 14, 2019

Accepted: July 5, 2019

DOI: $10.22146 /$ ijc. 45783

\begin{abstract}
In this study, the Box-Behnken Design (BBD) was employed to investigate the effects of wood particle size, pyrolysis temperature, and pyrolysis time on the production of wood vinegar from the Indonesian "bengkirai" wood (Shorea laevis Ridl). Characterization of wood vinegar was conducted by gas chromatography-mass spectrometry (GC-MS). Three variable designs consisting of wood particle size (2.00, 2.38, and $3.36 \mathrm{~mm}$ ), pyrolysis temperature $\left(350,400\right.$, and $\left.450{ }^{\circ} \mathrm{C}\right)$, and pyrolysis time $(105$, 120 , and $135 \mathrm{~min}$ ) were employed in a BBD response surface methodology (RSM-BBD). $R S M-B B D$ results suggested that maximum wood vinegar yield would be obtained with a wood particle size of $3.85 \mathrm{~mm}$, pyrolysis temperature of $400{ }^{\circ} \mathrm{C}$, and pyrolysis time of $93 \mathrm{~min}$. In addition, the mathematical model indicated the maximum wood vinegar yield would be $30.31 \%$. The main compounds in wood vinegar were acetic acid, 1-hydroxy-2propanone, furfural, 2,3-pentanedione, phenol, 2-methoxy phenol, 2-methoxy-4-methyl phenol, 2,6-dimethoxy phenol, and 1,2,4-trimethoxybenzene.
\end{abstract}

Keywords: wood vinegar; Shorea laevis; response surface methodology; Box-Behnken design; pyrolysis temperature; wood particle size

\section{- INTRODUCTION}

Wood vinegar, also known as pyroligneous acid, is a yellowish or dark brown condensate prepared from a wood or biomass carbonization process at a high temperature in the absence of oxygen [1]. Wood vinegar has been widely used as herbicide, insecticide, and fungicide [2-3]. For example, Hagner et al. [3] reported that wood vinegar from willow (Salid sp.) had insecticidal activity against Rhopalosiphum padi. Various studies have been reported about the effects of different types of wood, wood particle size (particle size), pyrolysis temperature and time on the yield of wood vinegar [4-7].

The wood types and pyrolysis temperature are primary factors for wood vinegar yield [7-8]. For example, $\mathrm{Ma}$ et al. [9] reported that wood vinegar yield from Rosmarinus officinalis leaves was 25\%, whereas those from Eucalyptus urograndis and Mimosa tenuiflora wood were 37.8 and $30.5 \%$, respectively [10]. Ratanapisit et al. [11] found that the maximum wood vinegar yield from rubber wood at a pyrolysis temperature of $550{ }^{\circ} \mathrm{C}$ was $27.45 \%$.

The response surface methodology (RSM) is a collection of mathematics- and statistics-based techniques that are useful for modeling and analysis of the effects of several independent variables, as well as the interactions between them. Its objectives are to optimize the response [12]. RSM has been successfully used to maximize wood vinegar yield from Euphorbia rigida [13] and palm kernel [14] by fast pyrolysis. Optimization of operating parameters and process of wood vinegar from Acacia mangium was studied by Crespo et al. [6], who found that optimum pyrolysis conditions were obtained at a temperature, heating rate, and particle size of $499.57^{\circ} \mathrm{C}, 12^{\circ} \mathrm{C} \mathrm{min}^{-1}$ and $0.46 \mathrm{~mm}$, respectively, for 
a yield of $33.13 \%$. Ngo et al. [14] used the RSM to study the effect of feedstock feed rate, the particle size of biomass, the temperature of pyrolysis, and residence time on the fast pyrolysis of palm kernel; the optimal wood vinegar yield was $49.50 \%$.

However, the wood vinegar made from Shorea laevis has not previously been tested for optimization of production and characterization. The Indonesian "bengkirai" wood has been used as a raw material in the home furniture industry, especially in West Kalimantan. The home furniture industry produces a huge volume of waste sawdust from wood. Therefore, the utilization of "bengkirai" sawdust to produce value-added materials would contribute to not only reducing waste but also to support local communities. The aim of this study was to predict the maximum yield of wood vinegar from the Indonesian "bengkirai" wood using the RSM-BBD. The chemical composition of wood vinegar was evaluated using gas chromatography-mass spectrometry (GC-MS).

\section{- EXPERIMENTAL SECTION}

\section{Materials}

The material was collected from a home furniture industry in Pontianak, Indonesia, converted into wood meals by a Willey mill and then air dried until reaching a moisture content of $12.5 \%$. The particle sizes of wood wastes were $2.00 \mathrm{~mm}$ (mesh number 10), $2.38 \mathrm{~mm}$ (mesh number 8 ), and $3.36 \mathrm{~mm}$ (mesh number 6 ).

\section{Procedure}

\section{Pyrolysis of wood and experimental design}

Pyrolysis of wood particles was conducted following the method described in Tranggono et al. [15] and Oramahi et al. [16]. The pyrolysis scheme in this study can be seen in Fig. 1. Particles were placed in a closed reactor that was then heated to the desired temperature of 350 ,
400, and $450{ }^{\circ} \mathrm{C}$, for pyrolysis times of 105,120 , and $135 \mathrm{~min}$, for 15 runs. The optimization procedure was designed based on a three-factor inscribed BBD with independent variables consisting of particle size: $2.00 \mathrm{~mm}, 2.38 \mathrm{~mm}$, and $3.36 \mathrm{~mm}$; pyrolysis temperature: 350,400 and $450{ }^{\circ} \mathrm{C}$; and pyrolysis time: 105,120 and $135 \mathrm{~min}$, using three levels of each variable for a total of 15 runs, as shown in Table 1 and 2.

BBD was applied to optimize wood-vinegar yield made from Shorea laevis. Particle size $\left(\mathrm{X}_{1}\right)$, pyrolysis temperature $\left(\mathrm{X}_{2}\right)$, and pyrolysis time $\left(\mathrm{X}_{3}\right)$ were the selected independent variables (Table 1 ). These variables were coded as a low, medium, or high for the RSM design points. As already mentioned, we used a BBD design for the experiment to regard the influence of the independent variables on the response [17-18].

For optimal point prediction, the second-order polynomial equation was:

$\mathrm{Y}=\beta_{0}+\sum_{\mathrm{i}=1}^{\mathrm{k}} \beta_{\mathrm{i}} \mathrm{X}_{\mathrm{i}}+\sum_{\mathrm{i}=1}^{\mathrm{k}} \beta_{\mathrm{ii}} \mathrm{x}_{\mathrm{i}}^{2}+\sum_{\mathrm{i}} \sum_{\mathrm{j}} \beta_{\mathrm{ij}} \mathrm{X}_{\mathrm{i}} \mathrm{X}_{\mathrm{j}}+\varepsilon$

where $X_{i}, X_{j}$ are the independent variables and $\beta_{0}, \beta_{i}, \beta_{i i}$, and $\beta_{\mathrm{ij}}$ are the regression coefficients [18-19]. To examine the predictive value, both formula's minimum and maximum values were used for canonical analysis.

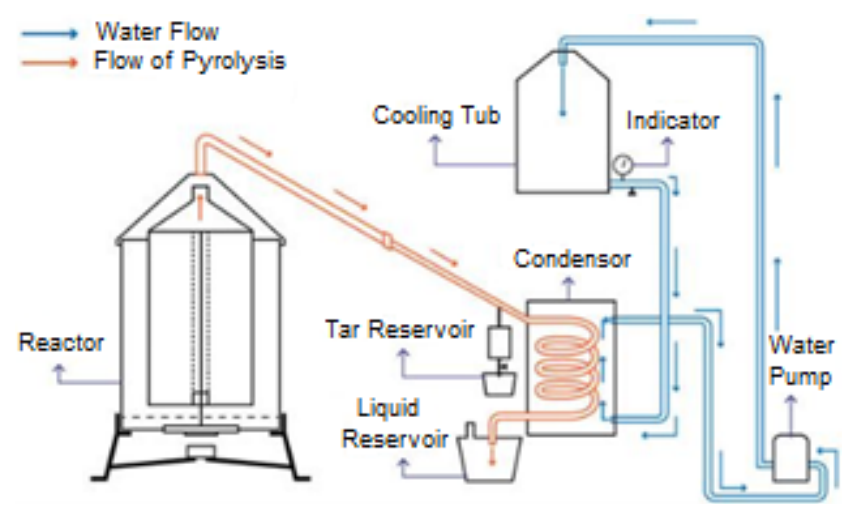

Fig 1. Pyrolysis device series scheme

Table 1. The level of the variable used for the Box-Behnken Design

\begin{tabular}{lcccc}
\hline & & \multicolumn{3}{c}{ Coded variable level } \\
\cline { 3 - 5 } Independent Variable & Symbol & Low & Center & High \\
\cline { 3 - 5 } & & -1 & 0 & 1 \\
\hline Wood particle size $(\mathrm{mm})$ & $\mathrm{X}_{1}$ & 2.00 & 2.38 & 3.36 \\
Pyrolysis temperature $\left({ }^{\circ} \mathrm{C}\right)$ & $\mathrm{X}_{2}$ & 350 & 400 & 450 \\
Pyrolysis time $(\min )$ & $\mathrm{X}_{3}$ & 105 & 120 & 135 \\
\hline
\end{tabular}


Table 2. The Box-Behnken design of the observed responses and predicted value for the wood vinegar yield from Shorea laevis

\begin{tabular}{cccccc}
\hline \multirow{2}{*}{ Run } & \multirow{2}{*}{$\mathrm{X}_{1}$} & $\mathrm{X}_{2}$ & $\mathrm{X}_{3}$ & \multicolumn{2}{c}{ Wood vinegar yield (\%) } \\
\cline { 5 - 6 } & & & & Observed & Predicted \\
\hline 1 & -1 & -1 & 0 & 5.89 & 8.22 \\
2 & -1 & 1 & 0 & 30.89 & 32.10 \\
3 & 1 & -1 & 0 & 28.89 & 27.68 \\
4 & 1 & 1 & 0 & 34.44 & 32.01 \\
5 & -1 & 0 & -1 & 25.33 & 23.00 \\
6 & -1 & 0 & 1 & 26.00 & 24.69 \\
7 & 1 & 0 & -1 & 28.89 & 30.19 \\
8 & 1 & 0 & 1 & 34.44 & 36.77 \\
9 & 0 & -1 & -1 & 17.56 & 17.46 \\
10 & 0 & -1 & 1 & 23.33 & 22.21 \\
11 & 0 & 1 & -1 & 31.00 & 32.12 \\
12 & 0 & 1 & 1 & 35.56 & 25.66 \\
13 & 0 & 0 & 0 & 26.67 & 28.37 \\
14 & 0 & 0 & 0 & 29.11 & 28.37 \\
15 & 0 & 0 & 0 & 29.33 & 28.37 \\
\hline
\end{tabular}

The ANOVA for the response of the surface quadratic model and the statistical significance of influence was analyzed by F-tests. The significance of each term was calculated using both the F-value and Prob $>$ F values, and larger F-values indicated the term was significant $[12,20]$.

\section{Characterization of wood vinegar}

Wood vinegar compound, retention time (RT), the relative percentage of the area from $S$. laevis Ridl were characterized using GC-MS (Shimadzu Manufacturing Co. Ltd, Kyoto, Japan, QP-210S). The GC-MS analysis conditions were as follows: capillary columns (DB-624); $30 \mathrm{~m} \times 0.25 \mathrm{~mm}$; temperature of injection: $250^{\circ} \mathrm{C}$; column temperature program: $60-200{ }^{\circ} \mathrm{C}$ and $\mathrm{He}$ flow rate: $40.0 \mathrm{~mL} / \mathrm{min}$. The GC-MS was arranged in the electron ionization mode at $70 \mathrm{eV}$ with an interface temperature of $200{ }^{\circ} \mathrm{C}$. Samples $(1 \mu \mathrm{L})$ were injected into a column and kept at $60-200^{\circ} \mathrm{C}$ with an increasing rate of $5{ }^{\circ} \mathrm{C} / \mathrm{min}$. The compounds were identified by comparison with the standard library data [16,21] and calculated by the integrated peak areas.

\section{Statistical analysis}

Statistica (version 6.0) and SAS (version 8.2, SAS
Institute Inc., NC. USA) were used for the analysis of the results of the BBD.

\section{- RESULTS AND DISCUSSION}

\section{Maximizing the Yield of Wood Vinegar from Indonesian "Bengkirai" Wood}

To determine the best combination of particle size $\left(\mathrm{X}_{1}\right)$, pyrolysis temperature $\left(\mathrm{X}_{2}\right)$, and pyrolysis time $\left(\mathrm{X}_{3}\right)$ within the range of $2.00-3.36 \mathrm{~mm}, 350-450{ }^{\circ} \mathrm{C}$, and 105-135 min, respectively, trials were designed based on a BBD. To maximize the wood vinegar yield, combinations of independent variables were selected (Table 2).

The stationer points in wood vinegar production were $3.85 \mathrm{~mm}$ for particle size $(1.50), 400{ }^{\circ} \mathrm{C}$ for pyrolysis temperature (0.05), and $93 \mathrm{~min}$ for pyrolysis time (-1.82). The calculated maximum wood vinegar yield was $30.31 \%$. Factors contributing to maximize wood vinegar yield were pyrolysis temperature and particle size [6]. The effect of pyrolysis time on wood vinegar yield was negligible in this study.

The higher wood vinegar yield at a higher temperature (Table 2) might have been due to the complete pyrolysis at these temperatures. Similar results were reported by Islam et al. [8] and Crespo et al. [6]. 
Crespo et al. [6] observed that wood vinegar yield from Acacia mangium ranged from $24.88-32.94 \%$ and that a high wood vinegar yield was obtained at higher temperatures of nearly $500^{\circ} \mathrm{C}$. In the present experiments, at the lower pyrolysis temperature of $350{ }^{\circ} \mathrm{C}$, the sawdust could not be completely decomposed, so that lower wood vinegar yields were obtained. A pyrolysis temperature of $300{ }^{\circ} \mathrm{C}$ resulted in lower vinegar yield than that of $450{ }^{\circ} \mathrm{C}$ [8]. Wu et al. [22] reported that the highest wood vinegar yield from Chinese fir (Cunninghamia lanceolata (Lamb.) Hook) sawdust reached $25 \%$ in the pyrolysis temperature range of $350-450{ }^{\circ} \mathrm{C}$, and that wood vinegar yield decreased to $21.22 \%$ with temperatures above $450{ }^{\circ} \mathrm{C}$. The yield of wood vinegar from walnut shell increased from 3.46 to $17.66 \%$ with a pyrolysis temperature increase from 140 to $290{ }^{\circ} \mathrm{C}$. The yield increase was mainly due to the increase of cellulose and lignin decomposition [23].

In addition, the lower particle size of $2.00 \mathrm{~mm}$ was likely to depress the oxygen supply, while at the higher particle size of $3.36 \mathrm{~mm}$, wood particles could be completely decomposed and higher wood vinegar yields obtained. Islam et al. [8] reported that the wastepaper feedstock producing a maximum percentage of the mass of liquid were 45 and $52 \%$ for particle sizes $0-1 \mathrm{~cm}$ and $1-2 \mathrm{~cm}$, respectively. The coefficient value $(\mathrm{CV})$ was 0.176 , representing a relatively good fit to response variables (Table 3).

The model regression coefficient of determination $\left(\mathrm{R}^{2}\right)$ was 0.9542 for wood vinegar yield, which indicated
95.42\% of the variability could be explained by the model, leaving only $4.58 \%$ residual variability for wood vinegar yield. Sofina and Islam [24] obtained similar results, with higher variability by the model. Oramahi et al. [5] reported that the higher $\mathrm{R}^{2}$ value showed that the model could be efficiently applied to predict wood vinegar yield. Table 3 shows that the main effects of the regression model were obtained by the t-test in the order of $\beta_{2}(7.42)>\beta_{1}(5.09)>\beta_{3}$ (2.18). This indicated that the $\mathrm{X}_{2}$ (pyrolysis temperature) and $\mathrm{X}_{1}$ (particle size) variables were the most important factors, with the strongest effect on wood vinegar yield. Meanwhile, $\mathrm{X}_{3}$ (pyrolysis time) was not a significant factor in wood vinegar yield $(\mathrm{p}<0.05)$.

As shown in Table 3, the coefficient of variation $(\mathrm{CV}=9.87 \%)$ was low, which indicated that the results had very high precision. Wang et al. [25] contended that the lower the $\mathrm{CV}$ value, the greater the reliability of the study. Fig. 2(a-c) show the three dimensional (3D) response surface curves of a graphical illustration of the effect of particle size, the temperature of pyrolysis, and pyrolysis time on wood vinegar yield.

As already mentioned, optimum conditions for particle size, pyrolysis temperature, and pyrolysis time were found to be $3.85 \mathrm{~mm}$ (1.50), $400{ }^{\circ} \mathrm{C}(0.05)$, and $93 \min (-1.82)$, respectively. The ANOVA for the quadratic model (Table 4 ) indicated that the contribution of the linear model was significant $(\mathrm{p}<0.05)$, while those of the quadratic and cross product were not.

Table 3. Regression coefficients of the predicted quadratic polynomial model

\begin{tabular}{lccrc}
\hline Sources of variation & Coefficient of polynomial & Error & t-value & $\operatorname{Pr}>\mathrm{t}$ \\
\hline Intercept & 28.37 & 1.55 & 18.34 & $<0.000$ \\
$\mathrm{X}_{1}$ & 4.82 & 0.95 & 5.09 & 0.004 \\
$\mathrm{X}_{2}$ & 7.03 & 0.95 & 7.42 & 0.000 \\
$\mathrm{X}_{3}$ & 2.07 & 0.95 & 2.18 & 0.081 \\
$\mathrm{X}_{1}{ }^{*} \mathrm{X}_{1}$ & -0.77 & 1.39 & -0.55 & 0.605 \\
$\mathrm{X}_{2} \mathrm{X}_{1}$ & -4.86 & 1.34 & -3.64 & 0.015 \\
$\mathrm{X}_{2} \mathrm{X}_{2}$ & -2.57 & 1.39 & -1.84 & 0.124 \\
$\mathrm{X}_{3} \mathrm{X}_{1}$ & 1.22 & 1.34 & 0.91 & 0.404 \\
$\mathrm{X}_{3} \mathrm{X}_{2}$ & -0.30 & 1.34 & -0.23 & 0.830 \\
$\mathrm{X}_{3} * \mathrm{X}_{3}$ & -1.07 & 1.39 & 0.76 & 0.480 \\
\hline Coefficient of variation $=9.87 \%, \mathrm{R}^{2}=0.95$ & & &
\end{tabular}

Hasan Ashari Oramahi et al. 
(a)

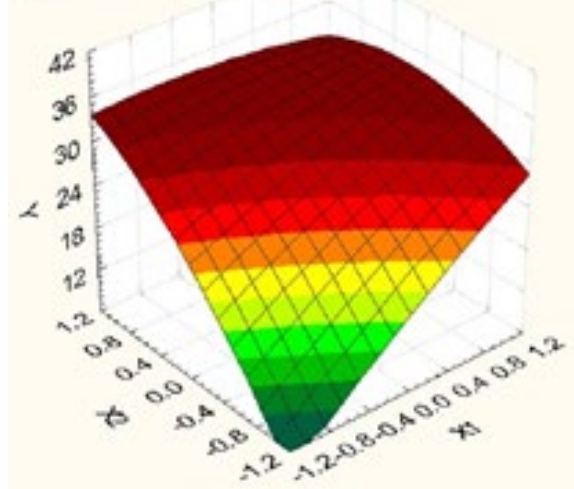

(b)

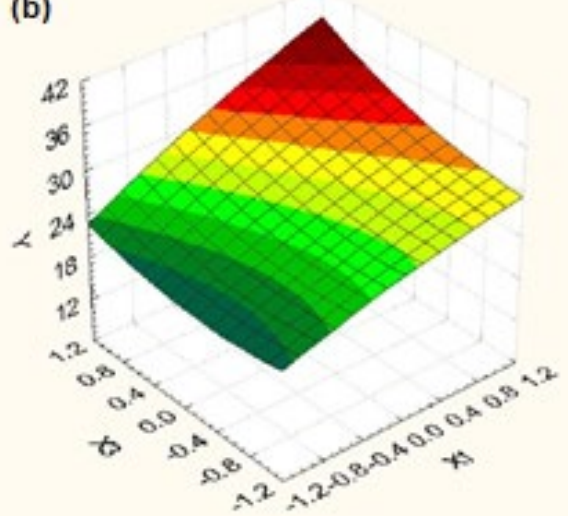

(c)

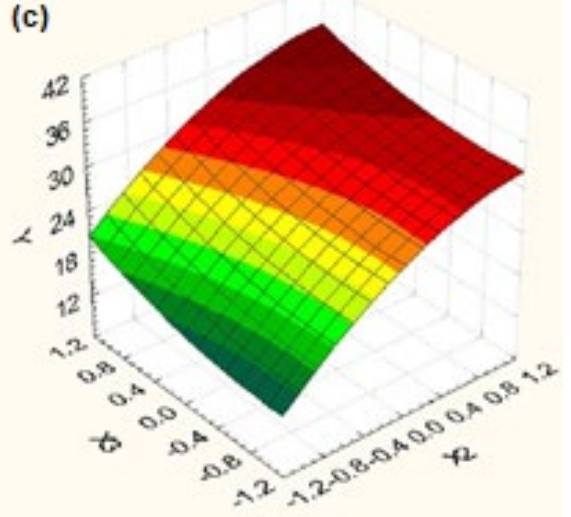

Fig 2. Response surface curve for wood vinegar yield showing the interaction between: (a) wood particle size $\left(\mathrm{X}_{1} ; \mathrm{mm}\right)$ and pyrolysis temperature $\left(\mathrm{X}_{2} ;{ }^{\circ} \mathrm{C}\right)$, (b) wood particle size $\left(\mathrm{X}_{1} ; \mathrm{mm}\right)$ and pyrolysis time $\left(\mathrm{X}_{3} ; \mathrm{min}\right)$, (c) pyrolysis temperature $\left(\mathrm{X}_{2} ;{ }^{\circ} \mathrm{C}\right)$ and pyrolysis time $\left(\mathrm{X}_{3} ; \mathrm{min}\right)$

Table 4. Analysis of variances (ANOVA) for quadratic model

\begin{tabular}{lcccc}
\hline Regression & $\mathrm{DF}$ & Sum of squares & $\mathrm{R}^{2}$ & $p$-value $($ prob $>\mathrm{F})$ \\
\hline Linear & 3 & 615.09 & 0.78 & 0.001 \\
Quadratic & 3 & 32.00 & 0.04 & 0.330 \\
Cross product & 3 & 109.90 & 0.13 & 0.064 \\
Total model & 9 & 747.98 & 0.95 & 0.007 \\
\hline
\end{tabular}

The responses of the BBD fitted with a second-order polynomial equation to illustrate the wood vinegar yield is given as follows:

$$
\begin{aligned}
\mathrm{Y}= & 28.7+4.82 \mathrm{X}_{1}+7.03 \mathrm{X}_{2}+2.07 \mathrm{X}_{3}-0.77 \mathrm{X}_{1}^{2}-2.57 \mathrm{X}_{2}^{2} \\
& -4.86 \mathrm{X}_{1} \cdot \mathrm{X}_{2}+1.22 \mathrm{X}_{1} \cdot \mathrm{X}_{3}-0.30 \mathrm{X}_{2} \cdot \mathrm{X}_{3}-6.67 \mathrm{X}_{3}^{2}
\end{aligned}
$$

\section{The Chemical Compound of Wood Vinegar from Shorea laevis}

Table 5 shows the GC-MS analysis data for the wood vinegar obtained from Shorea laevis Ridl at a pyrolysis temperature of $400{ }^{\circ} \mathrm{C}$ (optimum condition). As may be seen in Table 5, the main chemical compounds of the wood vinegar were acetic acid (4.96\%), 1-hydroxy-2propanone $(2.50 \%)$, furfural $(27.80 \%)$, phenol (15.26\%), mequinol (8.63\%), 4-methylphenol (3.00\%), and 2methoxy-4-methyl phenol (4.28\%). The amounts of acid and phenol content in wood vinegar were less than furfural. Thus it was assumed that pyrolysis temperature of $400{ }^{\circ} \mathrm{C}$ was optimal process condition for transforming the compound of wood vinegar to be furfural. In addition, the wood vinegar compound is affected by pyrolysis temperature, the particle size of wood and polymers of wood namely cellulose, hemicellulose, and lignin in the raw material [26-28]. Wu et al. [22] found that the acids compound of wood vinegar decreased as pyrolysis temperature was raised from 250 to $350{ }^{\circ} \mathrm{C}$, and the highest compound was $19.31 \%$ at $250{ }^{\circ} \mathrm{C}$, whereas the acid compound decreased to $9.96 \%$ at $350{ }^{\circ} \mathrm{C}$. However, for this study, the researcher focused only on wood vinegar obtained from Shorea laevis at a pyrolysis temperature of $400{ }^{\circ} \mathrm{C}$ which was characterized.

Nam et al. [29] stated that the main component of wood vinegar obtained from cotton stalk were acid, ketones, furans, and phenols. The furans and acids were furfural (30.54\%) and acetic acid (29.42\%), respectively. Meanwhile, Wei et al. [30] reported that the wood vinegar from walnut tree branches at $230-370{ }^{\circ} \mathrm{C}$ contained $32.68 \%$ phenols and $30.78 \%$ organic acid. The main acid was acetic acid, accounting for $22.62 \%$. They reported that wood vinegar showed the strongest antimicrobial activities to Phytophthora capsici, Colletotrichum orbiculare, Valsa mali, Cochliobolus sativus, Helminthosporium sativum, and Phytophthora infestan. The phenol and organic acid were active compounds of 
Table 5. The GC-MS analysis of wood vinegar obtained from Shorea laevis at the optimum temperature pyrolysis condition

\begin{tabular}{cclc}
\hline No & RT & Wood vinegar compound & Area (\% rel) \\
\hline 1 & 3.708 & Acetone & 4.56 \\
2 & 3.883 & Diazene & 2.02 \\
3 & 7.575 & Propanal & 1.30 \\
4 & 7.918 & Acetic acid & 4.96 \\
5 & 9.442 & 2,3-Pentanedione & 1.05 \\
6 & 9.589 & 1-Hydroxy-2-propanone & 2.52 \\
7 & 16.288 & Furfural & 27.80 \\
8 & 19.346 & Ethanone & 1.22 \\
9 & 21.424 & 2-Butanone & 3.98 \\
10 & 21.508 & 2-Propoxy butane & 2.99 \\
11 & 21.689 & 5-Methyl-2-furancarboxaldehyde & 6.40 \\
12 & 24.117 & Phenol & 15.26 \\
13 & 26.258 & Mequinol & 8.63 \\
14 & 27.165 & 4-Methyl phenol & 3.00 \\
15 & 29.776 & 2-Methoxy-4-methyl phenol & 4.28 \\
16 & 35.270 & 2,6-Dimethoxy phenol & 0.89 \\
\hline
\end{tabular}

wood vinegar for antimicrobial activity.

Zheng et al. [31] identified 25 chemical compounds by GC-MS analysis of wood vinegar prepared from giant reed (Arundo donax L.) at $300-600{ }^{\circ} \mathrm{C}$. The main components were acetic acid, phenols, aldehyde, ketone, alcohol, and esters. Meanwhile, Theapparat et al. [32] obtained wood vinegar from Garcinia mangostana Linn., Durio zibethinus L., and Lansium domesticum Serr., and found the main components were an organic acid, phenols, and methoxyphenols. Pimenta et al. [33] reported that wood vinegar from Eucalyptus urograndis contained 93 compounds: phenolics, furans, pyrans, esters, aldehydes and ketones, and that the main components were phenolics. Nakai et al. [34] demonstrated that wood vinegar from solid wood and wood-base composites could inhibit the growth of a white-rot fungus, T. versicolor, and a brown-rot fungus, $F$. palustris. The higher phenolic compounds in wood vinegar may have contributed to the increased inhibition against fungal growth. Phenols and organic acids are important compounds in wood vinegar's antifungal and antimicrobial activities, as well as its termiticidal activity. Two kinds of wood vinegar from the hull of spina date seed (HSDS) and the shell of peanut (PS) had 32 major compounds, and phenolics were dominant. The wood vinegar from HSDS and PS also showed antioxidant activity [35]. Hagner et al. [3] stated the pesticidal activity of wood vinegar obtained from willow (Salid sp.) and found total acid and acetic acid.

\section{- CONCLUSION}

The pyrolysis temperature and particle size variables were the most important factors with the strongest effect on wood vinegar yield. Optimization by the RSM-BBD the pyrolysis conditions for the maximum wood vinegar yield for the Indonesian "bengkirai" wood (Shorea laevis Ridl) was $3.85 \mathrm{~mm}$ particle size, $400{ }^{\circ} \mathrm{C}$ pyrolysis temperature, and $93 \mathrm{~min}$ in pyrolysis time, for a yield of $30.31 \%$. The predominant compounds in the wood vinegar were acetic acid, 1-hydroxy-2-propanone, furfural, 2,3-pentanedione, phenol, 2-methoxy phenol, 2-methoxy-4-methyl phenol, 2,6-dimethoxy phenol, and 1,2,4-trimethoxybenzene Further study are still required, in particular, concerning the effectiveness of wood vinegar for plant protection.

\section{- ACKNOWLEDGMENTS}

The authors would like to acknowledge the financial support of the Ministry of Research, Technology and Higher Education of Indonesia for 
financially supporting this project in the fiscal year 2018, through a research grant International research collaboration and scientific publication. We also thank the director of the Research Institute for Sustainable Humanosphere, Kyoto University, Japan, for providing facilities for this study.

\section{- REFERENCES}

[1] Lee, S.H., H'ng, P.S., Lee, A.N., Sajap, A.S., Tey, B.T., and Salmiah, U., 2011, Production of wood vinegar from lignocellulosic biomass and their effectiveness against biological attacks, J. Appl. Sci., 10 (20), 24402446.

[2] Tiirikkala, K., Fagernäs, L., and Tiilikkala, J., 2010, History and use of wood pyrolysis liquids as biocide and plant protection product, Open Agric. J., 4, 111118.

[3] Hagner, M., Tiilikkala, K., Lindqvist, I., Niemelä, K., Wikberg, H., Källi, A., and Rasa, K., 2018, Performance of liquids from slow pyrolysis and hydrothermal carbonization in plant protection, Waste Biomass Valorization, 1-12.

[4] Pinto, F., Paradela, F., Gulyurtlu, I., and Ramos, A.M., 2013, Prediction of liquid yields from the pyrolysis of waste mixtures using response surface methodology, Fuel Process. Technol., 116, 271-283.

[5] Oramahi, H.A., Wahdina, Diba, F., and Yoshimura, T., 2015, Optimization of production of lignocellulosic biomass bio-oil from oil palm trunk, Procedia Environ. Sci., 28, 769-777.

[6] Crespo, Y.A., Naranjo, R.A., Quitana, Y.G., Sanchez, C.G., and Sanchez, E.M.S., 2017, Optimisation and characterisation of bio-oil produced by Acacia mangium Willd wood pyrolysis, Wood Sci. Technol., 51 (5), 1155-1171.

[7] Akhtar, J., and Amin, N.S., 2012, A review on operating parameters for optimum liquid oil yield in biomass pyrolysis, Renewable Sustainable Energy Rev., 16 (7), 5101-5109.

[8] Islam, M.N., Beg, M.R.A., and Islam, R.I., 2005, Pyrolytic oil from fixed bed pyrolysis of municipal solid waste and its characterization, Renewable Energy, 30 (3), 413-420.
[9] Ma, C., Song, K., Yu, J., Yang, L., Zhao, C., Wang, W., Zu, G., and Zu, Y., 2013, Pyrolysis process and antioxidant activity of pyroligneous acid from Rosmarinus officinalis leaves, J. Anal. Appl. Pyrolysis, 104, 38-47.

[10] de Souza Araújo, E., Pimenta, A.S., Feijó, F.M.C., Castro, R.V.O., Fasciotti, M., Monteiro, T.V.C., and de Lima, K.M.G., 2018, Antibacterial and antifungal activities of wood vinegar from the wood of Eucalyptus urograndis and Mimosa tenuiflora, J. Appl. Microbiol., 124 (1), 85-96.

[11] Ratanapisit, J., Apiraksakul, S., Rerngnarong, A., Chungsiriporn, J., and Bunyakarn, C., 2009, Preliminary evaluation of production and characterization of wood vinegar from rubberwood, Songklanakarin J. Sci. Technol., 31 (3), 343-349.

[12] Montgomery, D.C., 2008, Design and analysis of experiments, John Wiley \& Sons, New York.

[13] Kiliç, M., Pütün, E., and Pütün, A.E., 2014, Optimization of Euphorbia rigida fast pyrolysis conditions by using response surface methodology, J. Anal. Appl. Pyrolysis, 110, 163-171.

[14] Ngo, T.A., Kim, J., and Kim, S.S., 2013, Fast pyrolysis of palm kernel cake using a fluidized bed reactor: Design of experiment and characteristics of bio-oil, J. Ind. Eng. Chem., 19 (1), 137-143.

[15] Tranggono, Suhardi, Setiadji, B., Darmadji, P., Supranto, and Sudarmanto, 1996, Identifikasi asap cair dari berbagai jenis kayu dan tempurung kelapa, ITEPA, 1 (2), 15-24.

[16] Oramahi, H.A., Yoshimura, T., Diba, F., Setyawati, D., and Nurhaida, 2018, Antifungal and antitermitic activities of wood vinegar from oil palm trunk, J. Wood Sci., 64 (3), 311-317.

[17] Liu, Y., Wei, S., and Liao, M., 2013, Optimization of ultrasonic extraction of phenolic compounds from Euryale ferox seed shells using response surface methodology, Ind. Crops Prod., 49, 837-843

[18] Yuan, Z., Xu, Z., Zhang, D., Chen, W., Zhang, T., Huang, Y., Gu, L., Deng, H., and Tian, D., 2018, Box-Behnken design approach towards optimization of activated carbon synthesized by co- 
pyrolysis of waste polyester textiles and $\mathrm{MgCl}_{2}, A p p l$. Surf. Sci., 427, 340-348.

[19] Srinivasa, P.C., Ravi, R., and Tharanathan, R.N., 2007, Effect of storage conditions on the tensile properties of eco-friendly chitosan films by response surface methodology, J. Food Eng., 80 (1), 184-189.

[20] Safari, M., Abdi, R., Adl, M., and Kafashan, J., 2018, Optimization of biogas productivity in lab-scale by response surface methodology, Renewable Energy, 118, 368-375.

[21] Mun, S.P., and Ku, C.S., 2010, Pyrolysis GC-MS analysis of tars formed during the aging of wood and bamboo crude vinegar, J. Wood Sci., 56 (1), 47-52.

[22] Wu, Q., Zhang, S., Hou, B., Zheng, H., Deng, W., Liu, D., and Tang, W., 2015, Study on the preparation of wood vinegar from biomass residues by carbonization process, Bioresour. Technol., 179, 98-103.

[23] Zhai, M., Shi, G., Wang, Y., Mao, G., Wang, D., and Wang, Z., 2015, Chemical compositions and biological activities of wood vinegar from the walnut shell, BioResources, 10 (1), 1715-1729.

[24] Sofina-E-Arab and Islam, M.A., 2015, Production of mahogany sawdust reinforced LDPE wood-plastic composites using statistical response surface methodology, J. For. Res., 26 (2), 487-494.

[25] Wang, X., Yang, G., Li, F., Feng, Y., and Ren, G., 2013, Response surface optimization of methane potentials in anaerobic co-digestion of multiple substrates: Dairy, chicken manure, and wheat straw, Waste Manage. Res., 31 (1), 60-66.

[26] Karagöz, S., Bhaskar, T., Muto, A., and Sakata, Y., 2005, Comparative studies of oil compositions produced from sawdust, rice husk, lignin and cellulose by hydrothermal treatment, Fuel, 84 (7-8), 875-884.

[27] Fan, Y., Cai, Y., Li, X., Yin, H., Yu, N., Zhang, R., and Zhao, W., 2014, Rape straw as a source of bio-oil via vacuum pyrolysis: Optimization of bio-oil yield using orthogonal design method and characterization of bio-oil, J. Anal. Appl. Pyrolysis, 106, 63-70.
[28] Mantilla, S.V., Gauthier-Maradei, P., Gil, P.Á., and Cárdenas, S.T., 2014, Comparative study of bio-oil production from sugarcane bagasse and palm empty fruit bunch: Yield optimization and bio-oil characterization, J. Anal. Appl. Pyrolysis, 108, 284294.

[29] Nam, H., and Capareda, S., 2015, Experimental investigation of torrefaction of two agricultural wastes of different composition using RSM (response surface methodology), Energy, 91, 507-516.

[30] Wei, Q., Ma, X., and Dong, J., 2010, Preparation, chemical constituents and antimicrobial activity of wood vinegar from walnut tree branches, J. Anal. Appl. Pyrolysis, 87 (1), 24-28.

[31] Zheng, H., Sun, C., Hou, X., Wu, M., Yao, Y., and Li, F., 2018, Pyrolysis of Arundo donax L. to produce pyrolytic vinegar and its effect on the growth of dinoflagellate Karenia brevis, Bioresour. Technol., 247, 273-281.

[32] Theapparat, Y., Khongthong, S., Rodjan, P., Lertwittayanon, K., and Faroongsarng, D., 2019, Physicochemical properties and in vitro antioxidant activities of wood vinegar prepared from brushwood biomass waste of Mangosteen, Durian, Rambutan, and Langsat, J. For. Res., 30 (3), 1139-1148.

[33] Pimenta, A.S., Fasciotti, M., Monteiro, T.V., and Lima, K.M., 2018, Chemical composition of wood vinegar obtained from Eucalyptus GG100 Clone, Molecules, 23 (2), 426.

[34] Nakai, T., Kartal, S.N., Hata, T., and Imamura, Y., 2007, Chemical characterization of pyrolysis liquids of wood-based composites and evaluation of their bio-efficiency, Build. Environ., 42 (3), 1236-1241.

[35] Li, Z., Zhang, Z., Wu, L., Wang, J., Liu, Z., Zhang, Z., and Wang, Z., 2017, Preparation and characterization of two wood vinegar obtained from the hull of spina date seed and shell of peanut, Chem. Res. Chin. Univ., 33 (3), 348-353. 